\title{
Microstructural and Physical Characteristics of Recycling Aluminium Chips AA6061/Al Powder Using Powder Metallurgy
}

\author{
Muhammad Irfan Ab Kadir ${ }^{\# 1}$, Mohammad Sukri Mustapa ${ }^{\# 2}$, Waluyo Adi Siswanto*3, \\ Ahmed Sahib Mahdi ${ }^{\# 4}$, Mohd Arif Samsi ${ }^{\# 5}$ \\ \# Structural Integrity and Monitoring Research Group (SIMReG) of Mechanical and Manufacturing \\ Engineering, UTHM, 86400 Parit Raja, Batu Pahat, Johor, Malaysia \\ ${ }^{1}$ irfankadir91@gmail.com \\ sukri@uthm.edu.my \\ ${ }^{4}$ ahmedaltaei@yahoo.com \\ 5 arif_samsi90@yahoo.com \\ * Ffaculty of Mechanical and Manufacturing Engineering, Universiti Tun Hussein Onn Malaysia (UTHM) \\ Johor, 86400 Parit Raja, Batu Pahat, Johor, Malaysia \\ ${ }^{3}$ waluyo@uthm.edu.my
}

\begin{abstract}
Solid state recycling of AA6061 chips by cold compression is a current approach processing technique that uses remarkably lower energies and operating cost compared to conventional recycling by casting. In this study, recycled AA6061 chips together with Al powder were fabricated to form a sample by combination of powder metallurgy and compaction technique. The effects of various Al powder content on the microstructure of the recycling AA6061/Al sample were investigated. The density, apparent porosity, water absorption and hardness of the composites were also examined. It was observed that the Al powders in the AA6061/Al composites were distributed non-homogeneously and randomly between the AA6061 chip regions. The density decreased gradually with the addition of Al powder rise back at 70 wt \% content of Al powder until it reaches full Al powder. The density of sample full chips and full powder shows the closest value to theoretical at $2.47 \mathrm{~g} / \mathrm{cm}^{3}$ and $2.43 \mathrm{~g} / \mathrm{cm}^{3}$ respectively. The full Al chips showed the highest hardness at $65.6 \mathrm{Hv}$ and gradually decreased with the increasing of Al powder content.
\end{abstract}

Keyword - Aluminium, recycling chip, powder metallurgy, microstructure, physical characteristic

\section{INTRODUCTION}

The global production of alumina for primary aluminium has escalated dramatically in the past 100 years [1]. The production of primary aluminium increases effectively until to the recent years. Meanwhile, the development of high strength $\mathrm{Al}$ alloys for aerospace and automobile applications is increasing due to the importance of realizing extended lifetimes for the structural components fabricated from these alloys [2]. Interest for aluminium items is expanding since aluminium combination offers superb corrosion resistance with great strength and low density. Because of expanding of interest of this metal, waste issue is a standout amongst the most famous issues that have gotten broad public extension regardless of the increasing usage of aluminium used today is originating from recycled automotive components [3].

This reason justifies the need for further research on the recovery infrastructure and recycling of automotive aluminium. Although machining can be an expensive and undesirable manufacturing process, it is essential for high surface quality of the manufactured material. Machining has been used in the aerospace and automotive industries for Al alloy manufacturing. One factor contributing to its expensiveness is the high proportion of waste that is generated [4]. Furthermore, finishing process in industry generates waste usually in chip form but recycling of chip is difficult due to their elongated spiral shape and micro size nature. Their surface area is relatively large and covered with oil emulsion which it is not effective for recycling through re-melting approach [5].

Aluminium scrap has considerable market value because most of the energy required for the production of primary aluminium is embodied in the metal itself and, consequently, in the scrap. Therefore, the energy needed to melt aluminium scrap is only a fraction of that required for primary aluminium production. Furthermore, if pre-treated and/or sorted, aluminium products can be recycled for use in almost all aluminium applications since the metal's atomic structure is not altered during melting. Thus, aluminium can be recycled over and over again without loss of properties. The high value of aluminium scrap is a key incentive and major economic impetus for recycling [6]. 
A number of studies researchers have reported that the solid state recycling of $\mathrm{Al}$ alloys have been successfully carried out using powder metallurgy method. Roshan et al. [7] studied that the microstructure and tensile properties of nano-composite $\mathrm{Al} 2014-4 \mathrm{wt} . \% \mathrm{Al}_{2} \mathrm{O}_{3}$ produced from machining chips using ball milling and hot extrusion stated that $\mathrm{Al}_{2} \mathrm{O}_{3}$ nano-particles were very well introduced and dispersed in the $\mathrm{Al} 2014$ matrix after the milling of the particles together for 24 hours. They identified an intergranular fracture of extrude particles that was accelerated by weak grain boundaries. A new approach was used by Fogagnolo et al. in which the aluminium chips is directly cold or hot pressed and then hot extruded. Without the milling process, the technique resulting more economic recycling process [8]. AA7075 chips with addition of pure Al powder was recycled through powder metallurgy method was conducted by Sherafat et al. [9]. Significantly, large area of application and high demand of aluminium has made the study of aluminium recycling becoming more and more interesting [10].

Aluminium recycling benefits present and future generations by conserving energy and other natural resources. Therefore, this research works on recycled AA6061 chips fabricated with Al powder AA6061 by combination of powder metallurgy and compaction technique in order to study the mechanical and physical properties of composites.

\section{EXPERIMENTAL PROCEDURE}

\section{A. Material}

In this study, AA6061 alloy with a theoretical density of $2.7 \mathrm{~g} / \mathrm{cm}^{3}$ was used as the metal matrix material. The AA6061 alloy blocks were supplied by the Newspark Technology Co., Ltd., China. Meanwhile, Al powder used in this study comes with an average particle size of $25 \mu \mathrm{m}$ and was supplied by Chengdu Best New Materials Co., Ltd., China. The chemical composition (in wt.\%) of the AA6061 alloy are $\mathrm{Si}(0.59), \mathrm{Fe}(0.092), \mathrm{Cu}(0.289)$, $\mathrm{Mn}(0.08), \mathrm{Mg}(0.975), \mathrm{Cr}(0.2), \mathrm{Zn}(0.031), \mathrm{Ti}(0.1)$, and $\mathrm{Al}$ (remnant). Zinc stearate was used as a binder to make the compaction process easier [11].

\section{B. Preparation of chip}

Firstly, chip was produced by using CNC milling machine, type HSM (SODICK - MC430L) as shown in Fig 1. The feed rate $(1100 \mathrm{~mm} / \mathrm{min})$, depth of cut $(1.0 \mathrm{~mm})$, cutting velocity $(345.4 \mathrm{~m} / \mathrm{min})$ were used as the parameters of machine to produce the chips. Milled aluminium were then cleaned by ultrasonic bath apparatus type Fritsch (ultrasonic cleaner labarette 17). The duration was 1 hour for each batch. After that, it was treated with acetone solution to remove oil, grease and any impurities left for 20 minutes. Finally, the drying process was used by conventional drying oven for 1 hour to dry up the acetone solution or any moisture on the chips produced.

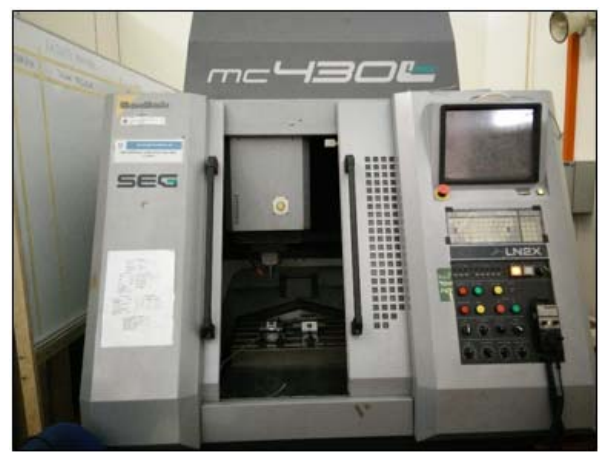

(a)

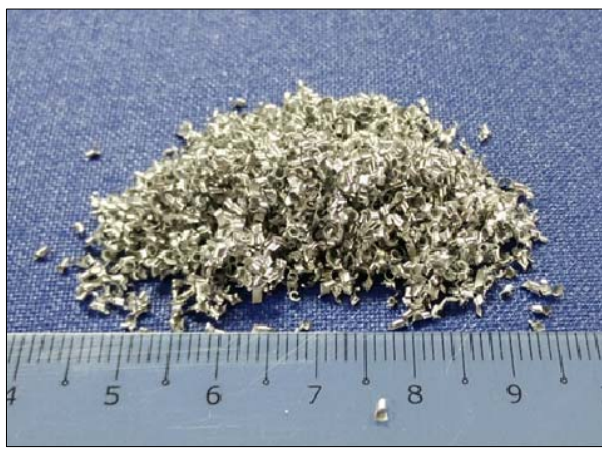

(b)

Fig 1. (a) High speed milling machine (SODICK - MC430L) and (b) aluminium chips produced.

\section{Compaction Process}

The compaction process used was uniaxial hydraulic press machine. The hydraulic machine brand is Carver model 3851-0. The powder was poured into the mould, then mould was closed to be compress into a shape called green compact [12]. The compaction load was set at 9 tons with holding time of 20 minutes [13]. The cleaned surfaces of die wall and tools (upper and lower punch) were sprayed with a lubricant-saturated solution to ease the removal of sample. The classification of mixture between Al chip and powder is as shown in Table 1 . 
TABLE 1. The classification of samples in weight percentage.

\begin{tabular}{ccc}
\hline Denotation & Al chip (wt.\%) & Al powder (wt.\%) \\
\hline A1 & 100 & 0 \\
A2 & 90 & 10 \\
A3 & 70 & 30 \\
A4 & 50 & 50 \\
A5 & 30 & 70 \\
A6 & 10 & 90 \\
A7 & 0 & 100 \\
\hline
\end{tabular}

\section{Sintering process}

Sintering process is to provide extra bonding between atoms. The atomic diffusion takes place and welded areas formed during compaction will increase the connection by sintering process. This process was conducted in a tube furnace machine. The specimens were heated by furnace in a controlled atmosphere. The model of tube furnace used is HTF 1800 and Carbolite branded. This sintering was operated using Argon gas as an inert gas. The temperature used in this process is $552^{\circ} \mathrm{C}$ and the sintering profile as shown in Fig 2 [14].

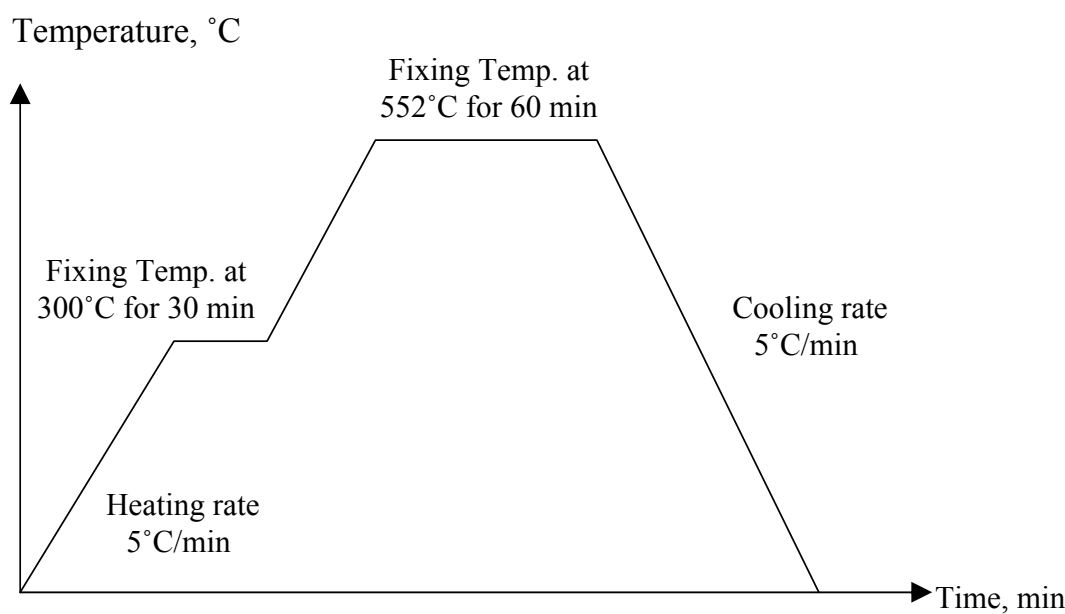

Fig 2. Sintering profile [14]

\section{III.RESULT AND DISCUSSION}

\section{A. Microstructural Behaviour}

The success of the recycling of chips by cold compaction and sintering with the quality of the consolidated samples depend strongly on the resulting microstructure. The microstructures of the sintered samples were characterized using optical microscopy. Fig 3 shows the microstructure of AA6061 chips and powder samples with different composition. It should be noted that the densification behaviour of the mixture of chip and powder depends on the compressibility of the AA6061 chips and powders. The magnifications used in this image were at 50 and 200 times magnifications in order to get clear differentiation between chips and powder.

For sample A1 (full chips), it can be seen many of large pores formed on the surface due to the large chips size. When Al powders were added gradually and mix with the chips, it can be seen that the pores become less and the formation of grain boundaries also can be seen. The Al powders tries to filling up the gaps of AA6061 chips left and covering the pores and forming a good surface on the sample. Whereas at full Al powders (sample A7), although the bonding and grain boundaries becomes more but there were still small pores formation on the surface of sample. This can be attributed to the effect small particles size of Al powders in filling the porosities, which decreased the porosity between AA6061 chips and consequently increased the densification behaviour of the chip-powder mixtures. The size of pores in the contact region of the AA6061 chips was very high, and so the fine Al powders could easily fill these regions

Meanwhile, increasing pore size was correlated directly with an increase in the irregularity of pore shape. The irregularity of AA6061 chip sizes resulted in the higher porosity and random pore shapes. Significantly, as more $\mathrm{Al}$ powder added into the sample resulted in less pores formation, smaller average pore size, and more spherical pore shape [15]. 
(a)

(b)

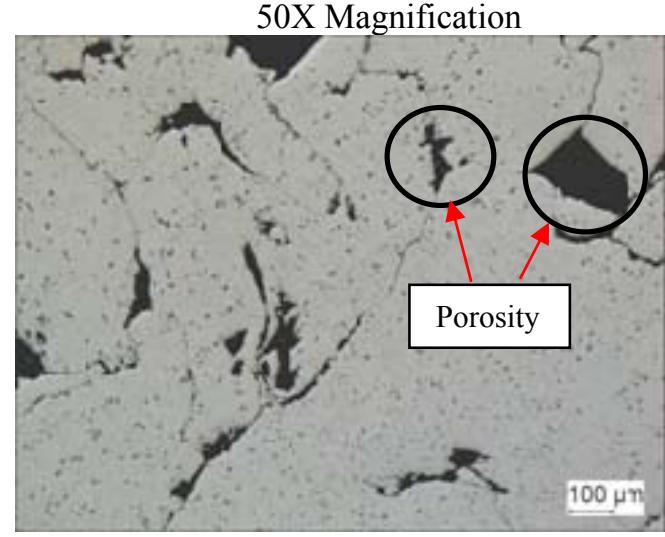

50X Magnification

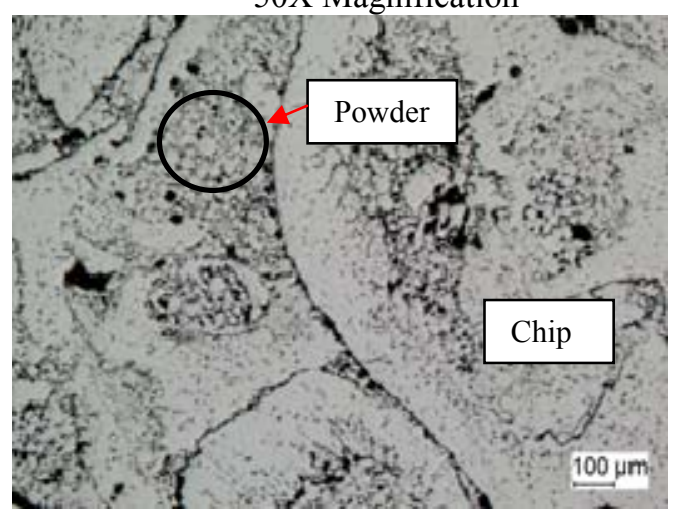

(c)

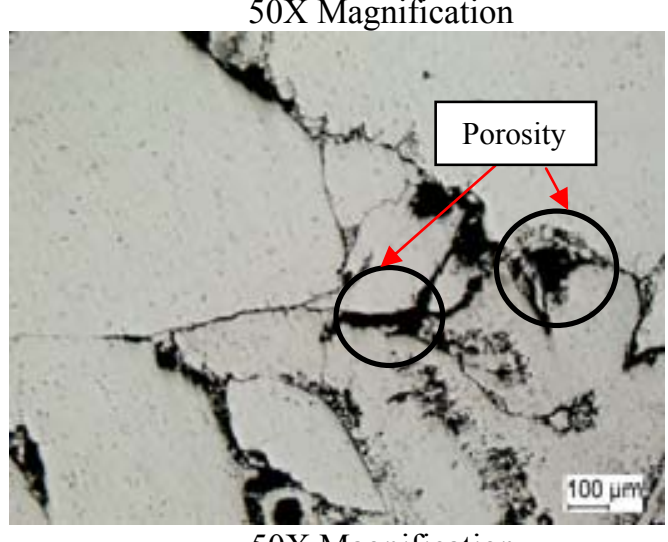

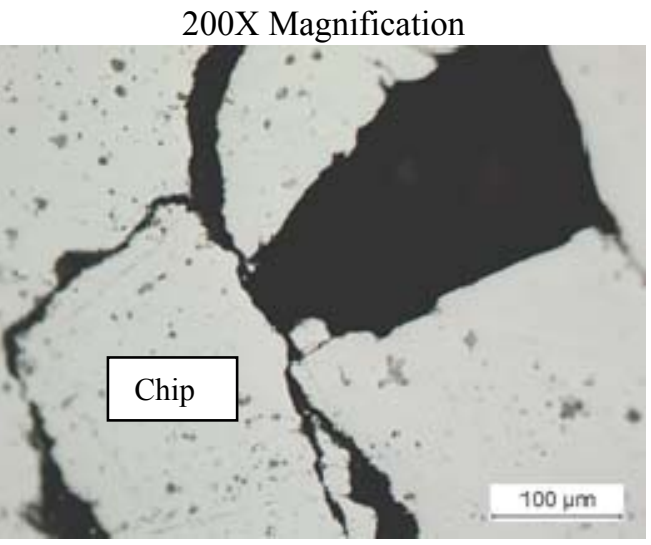

200X Magnification

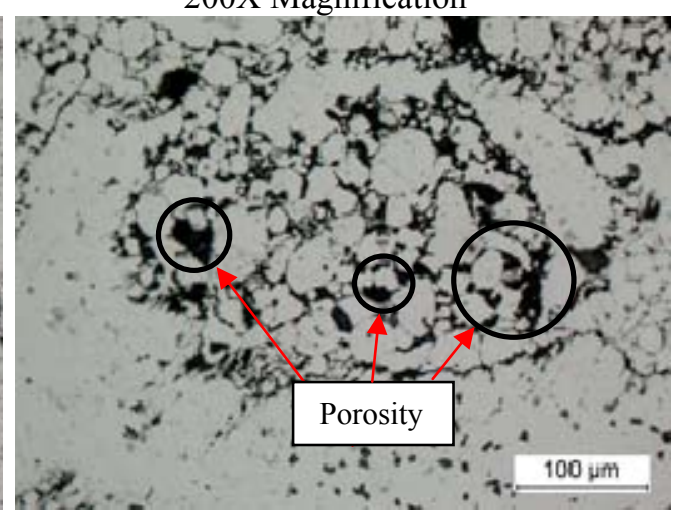

200X Magnification

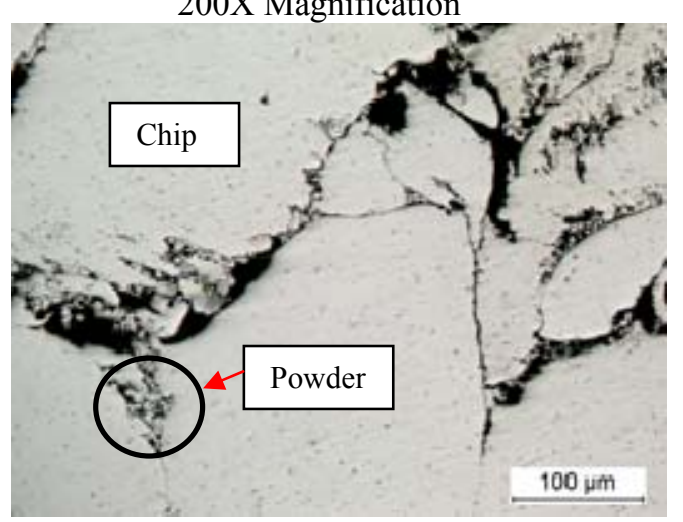

200X Magnification

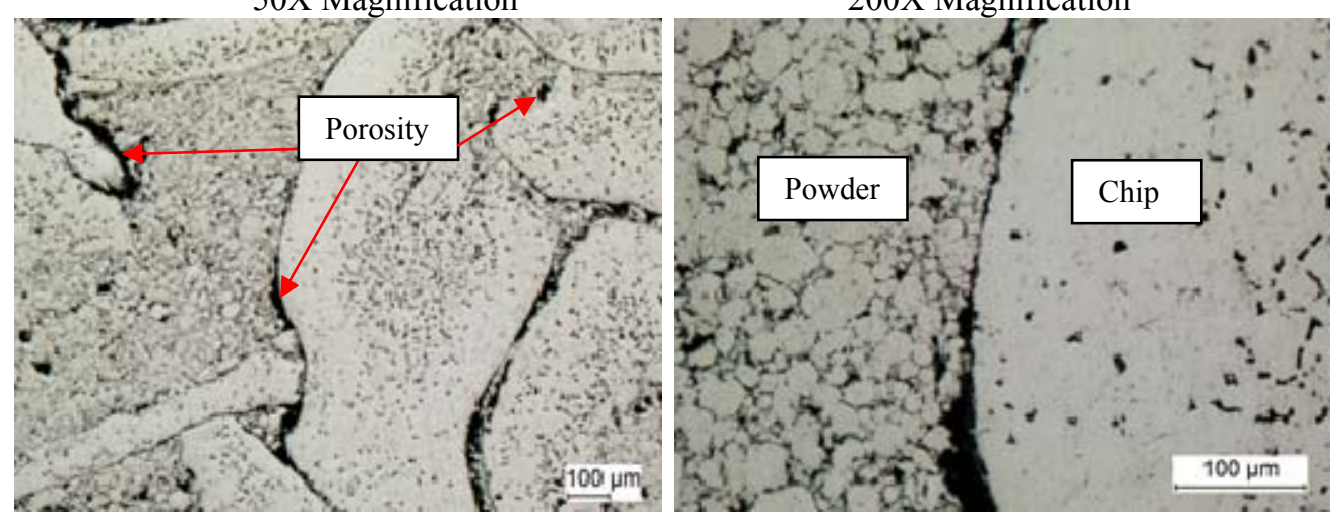


(e)
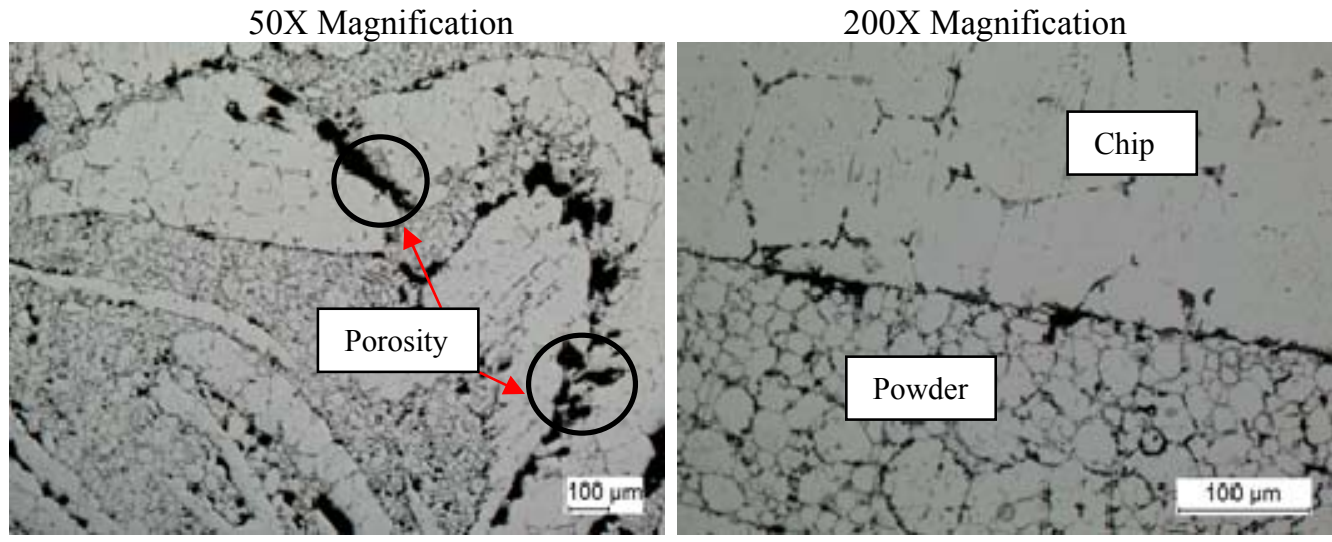

(f)

50X Magnification

200X Magnification

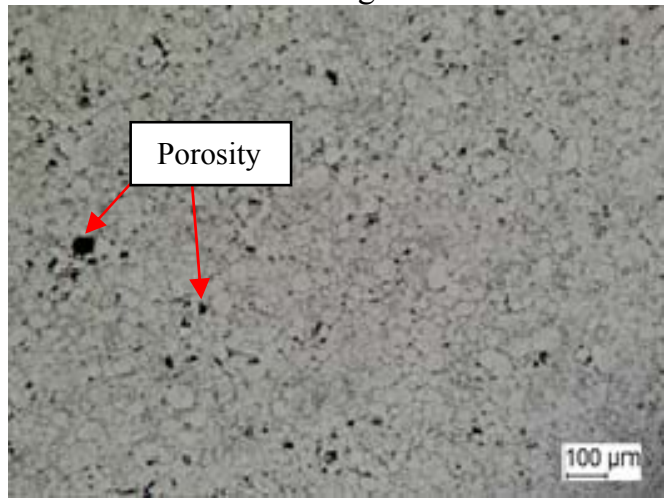

50X Magnification

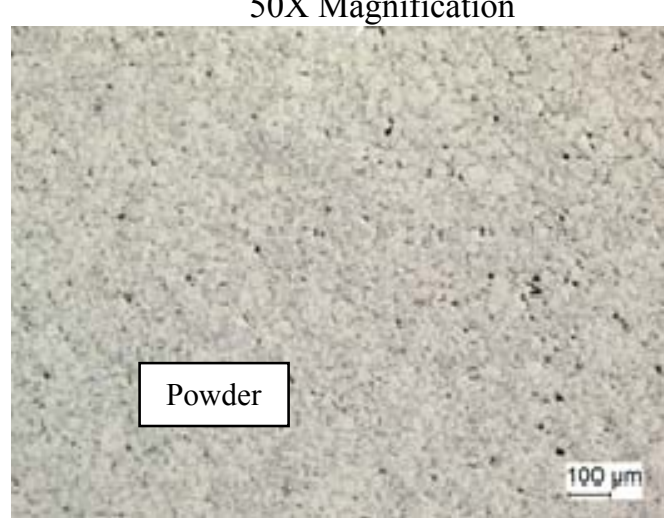

200X Magnification
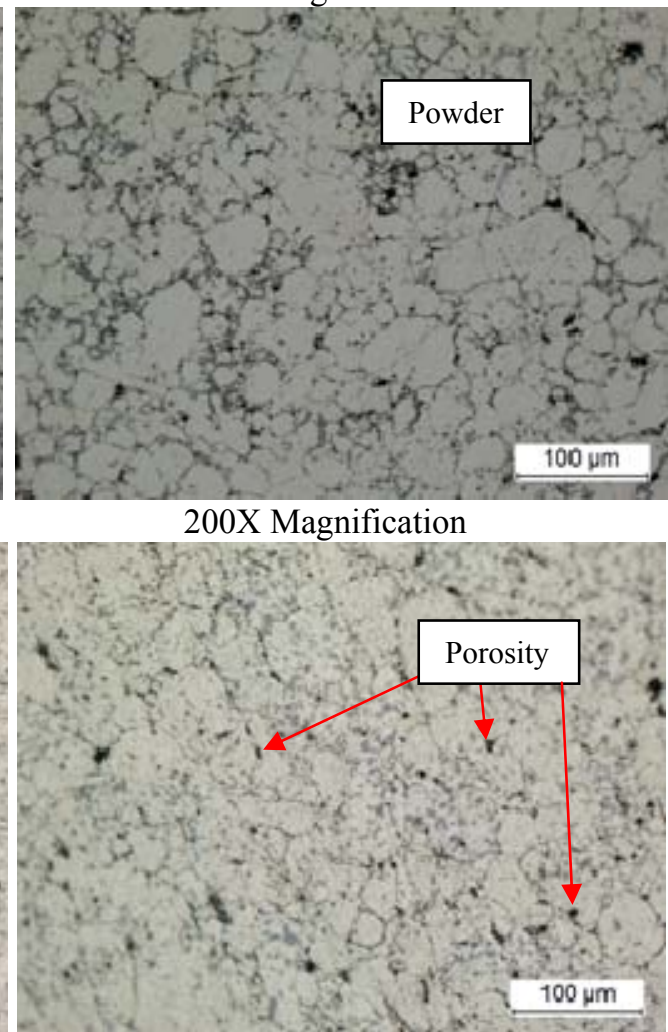

Fig 3. Optical microscopy images of AA6061 chips and powder samples after sintered: (a) A1, (b) A2, (c) A3, (d) A4, (e) A5, (f) A6, and (g) A7

\section{B. Physical properties}

The relationship between the density, apparent porosity and water absorption of AA6061 chips/Al powder samples with different ratios of chips and powder were identified through Archimedes' technique. Thus, Table 2 provides the results of density, apparent porosity and water absorption. From the graph in Fig 4, it is apparent that the density of sample full chips and full powder shows the closest value to theoretical density at $2.47 \mathrm{~g} / \mathrm{cm}^{3}$ and $2.43 \mathrm{~g} / \mathrm{cm}^{3}$ respectively. While, the density decreased gradually with the addition of $10 \mathrm{wt} \%, 30 \mathrm{wt} \%$ and 50 $\mathrm{wt} \% \mathrm{Al}$ powder. The density rise back at $70 \mathrm{wt} \%$ content of $\mathrm{Al}$ powder until it reaches full $\mathrm{Al}$ powder.

Apparent porosity always refers to the fraction or percentage of pores within the volume of a porous solid. Here we can see that the highest porosity occurs when the amount of Al chip and powder content was at $50 \mathrm{wt} \%$. The increasing of Al powder after $50 \mathrm{wt} \%$ will reduce the percentage of porosity and similar effect also occurs when increasing the amount of Al chip.

Interestingly, the water absorption also gave the same reaction with the apparent porosity, whereby, the 50 $\mathrm{wt} \%$ of Al chip and powder indicates the changes after adding or reducing the amount of $\mathrm{Al}$ powder. The lowest water absorption was $1.56 \%$ at full $\mathrm{Al}$ chip while; full $\mathrm{Al}$ powder was very close by at $2.11 \%$.

Significantly, changes of density, apparent porosity and water absorption can be analysed as increasing sintered density resulted in lower pore fraction and as well as less percentage of water absorption. 
TABLE 2. The value of density, apparent porosity and water absorption.

\begin{tabular}{cccc}
\hline Specimens & Density (g/cm $\left.\mathbf{c m}^{\mathbf{3}}\right)$ & Apparent Porosity (\%) & Water Absorption (\%) \\
\hline A1 & 2.47 & 2.27 & 1.56 \\
A2 & 2.43 & 2.73 & 1.83 \\
A3 & 2.38 & 6.27 & 4.35 \\
A4 & 2.33 & 10.57 & 7.34 \\
A5 & 2.34 & 10.45 & 7.22 \\
A6 & 2.37 & 5.05 & 3.56 \\
A7 & 2.42 & 3.06 & 2.11 \\
\hline
\end{tabular}

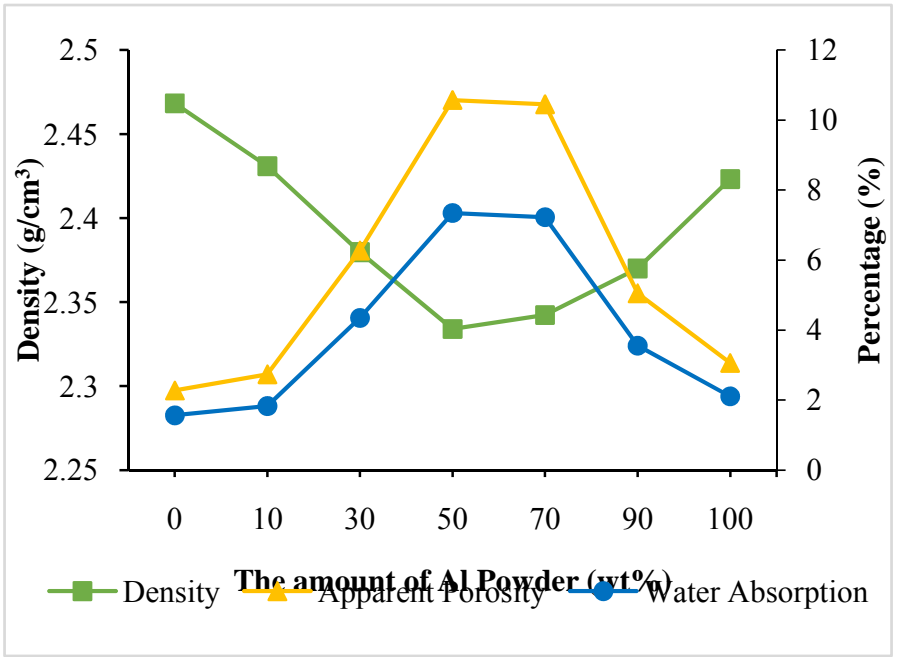

Fig 4. The changes of density $\left(\mathrm{g} / \mathrm{cm}^{3}\right)$, apparent porosity (\%) and water absorption (\%) with the increasing of $\mathrm{Al}$ powder content.

\section{Microhardness}

The hardness test was carried out to find out the degree of hardness of the material surface by using small load. In this test, the hardness test was conducted using the micro Vickers hardness machine in which the instrument consists of a hard and accurate head for easing the penetrating in the material. Five values from each sample were taken to calculate the average. Fig 5 illustrates the relationship between hardness and various loadings of Al chips and Al powder content. The full Al chips showed the highest hardness at $65.6 \mathrm{Hv}$ and gradually decreased with increasing $\mathrm{Al}$ powder content while, the full Al powder gave the lowest hardness at $42.0 \mathrm{Hv}$.

Significantly, the hardness decreased with an increasing amount of Al powder. Having said that, the hardness values showed an irregular distribution for all $\mathrm{Al}$ powder contents. It is clearly to understand that the $\mathrm{Al}$ powders can move and reposition themselves between the Al chips, leading to an increase in the amount of porosity.

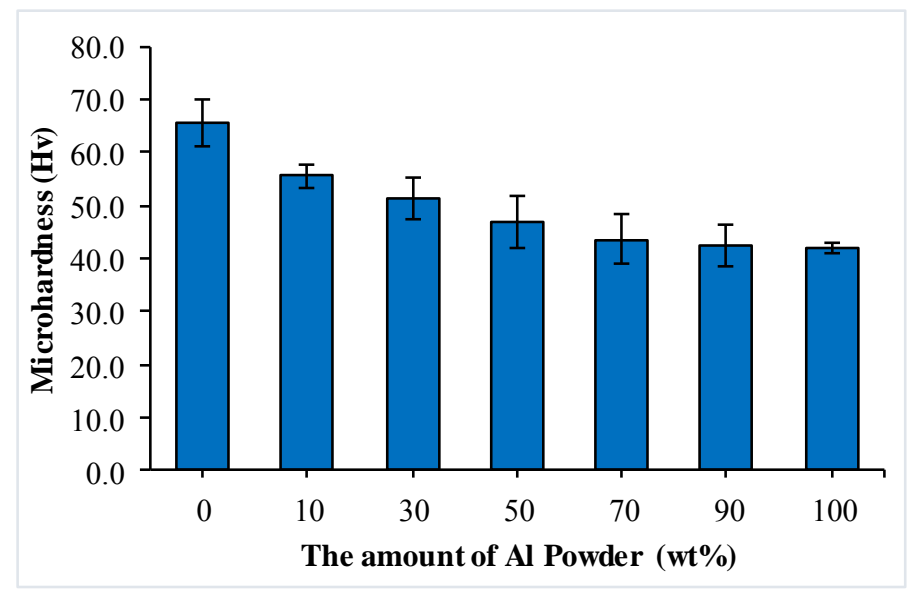

Fig 5. Microhardness (Hv) against ratios of recycled Al chips/Al powder samples. 


\section{IV.CONCLUSION}

Based on the production and characterization of sample made of recycled AA6061 chips and Al powders, the following conclusions can be drawn. The addition of Al powder managed to form a good microstructure with less formation of large pores on the surface of a sample. The sintered density of sample full chips and full powder shows the closest value to theoretical at $2.47 \mathrm{~g} / \mathrm{cm}^{3}$ and $2.42 \mathrm{~g} / \mathrm{cm}^{3}$ respectively. Significantly, changes of density, apparent porosity and water absorption can be analysed as increasing sintered density resulted in lower porosity and as well as less percentage of water absorption. Meanwhile, the full Al chips showed the highest hardness at $65.6 \mathrm{Hv}$ and gradually decreased with increasing Al powder content while, the full Al powder gave the lowest hardness at $42.0 \mathrm{Hv}$ due to the rearrangement of Al powder between the AA6061 chips.

\section{ACKNOWLEDGMENT}

This work is supported by the Office for Research, Innovation, Commercialization and Consultancy Management (ORICC) E15501. The authors would also like to acknowledge the assistance provided by Universiti Tun Hussein Onn Malaysia.

\section{REFERENCES}

[1] R. Lumley, Fundamentals of Aluminium Metallurgy: Production, Processing and Applications. UK: Woodhead Pub., 2011.

[2] A. Meyveci, İ. Karacan, U. Çalıgülü, and H. Durmuş, "Pin-on-disc characterization of 2xxx and 6xxx aluminium alloys aged by precipitation age hardening," J. Alloys Compd., vol. 491, no. 1, pp. 278-283, 2010.

[3] E. Ghassemieh, Materials in automotive application, state of the art and prospects. INTECH Open Access Publisher, 2011.

[4] P. Luo, D. T. McDonald, S.-M. Zhu, S. Palanisamy, M. S. Dargusch, and K. Xia, "Analysis of microstructure and strengthening in pure titanium recycled from machining chips by equal channel angular pressing using electron backscatter diffraction," Mater. Sci. Eng. A, vol. 538, pp. 252-258, 2012.

[5] J. A. S. Green, Aluminum recycling and processing for energy conservation and sustainability. ASM International, 2007.

[6] G. A. R. Committee, "Global Aluminium Recycling: A Cornerstone of Sustainable Development, International Aluminium Institute, London." International Aluminium Institute, London, 2009.

[7] M. R. Roshan, M. Mirzaei, and S. A. J. Jahromi, "Microstructural characteristics and tensile properties of nano-composite Al 2014/4wt.\% Al2O3 produced from machining chips,” J. Alloys Compd., vol. 569, pp. 111-117, 2013.

[8] J. B. Fogagnolo, E. M. Ruiz-Navas, M. A. Simón, and M. A. Martinez, "Recycling of aluminium alloy and aluminium matrix composite chips by pressing and hot extrusion," J. Mater. Process. Technol., vol. 143, pp. 792-795, 2003.

[9] Z. Sherafat, M. H. Paydar, and R. Ebrahimi, "Fabrication of Al7075/Al, two phase material, by recycling Al7075 alloy chips using powder metallurgy route," J. Alloys Compd., vol. 487, no. 1, pp. 395-399, 2009.

[10] H. A. Mashhadi, A. Moloodi, M. Golestanipour, and E. Z. V Karimi, "Recycling of aluminium alloy turning scrap via cold pressing and melting with salt flux,” J. Mater. Process. Technol., vol. 209, no. 7, pp. 3138-3142, 2009.

[11] A. S. Mahdi, M. S. Mustapa, M. A. Lajis, and M. W. Abd Rashid, "Effect of Holding Time on Mechanical Properties of Recycling Aluminium Alloy AA6061 Through Ball Mill Process," Int. J. Mech. Eng. Technol., vol. 6, no. 9, pp. 133-142, 2015.

[12] E. Paul Degarmo, J. T. Black, and A. K. Ronald, "Materials and processes in manufacturing," Eight Ed. Prentice-Hall India, 1997.

[13] A. S. Mahdi, M. S. Mustapa, M. A. Lajis, M. Warikh, and A. Rashid, "Effect of Compaction Pressure on Physical Properties of Milled Aluminium Chip ( AA6061 ),” Int. J. Sci. Res., vol. 4, no. 9, pp. 1759-1764, 2015.

[14] M. S. Mustapa, A. S. Mahdi, and M. A. Lajis, "Physical Properties of Recycling Milled Aluminium Chip ( AA6061 ) for Various Sintering Temperature," Int. J. Mech. Ind. Technol., vol. 3, no. 2, pp. 33-40, 2016.

[15] W. B. James and H. Corporation, "Powder Metallurgy Methods and Applications," in ASM Handbook Volume 7: Powder Metallurgy, vol. 7, C. and J. W. N. Prasan K. Samal, Ed. ASM International, 2015, pp. 9-19(11). 